\title{
IDENTIFIKASI LALAT BUAH (Diptera: Tephritidae) PADA KEBUN JERUK DI KECAMATAN RAMBAH SAMO KABUPATEN ROKAN HULU
}

\author{
Via Fitriani $^{1 *}$, Ria Karno ${ }^{1}$, Eti Meirina Brahmana ${ }^{1}$ \\ ${ }^{1}$ Program Studi Pendidikan Biologi Fakultas Keguruan Dan Ilmu Pendidikan \\ Universitas Pasir Pengaraian \\ Jl. Tuanku Tambusai Kumu Desa Rambah Kecamatan Rambah Hilir. Pasir Pengaraian \\ *Email: fitrianiviaa@gmail.com
}

\begin{abstract}
This research aims to determine species of fruit flies (Diptera: Tephritidae) the attacking orange plantion Rambah Samo District Rokan Hulu Regency. Study was conducted in March to May 2018, using a survey method with technique sampling purposive sampling. The research found 6 species with a total of 236 individuals. The species is Bactrocera umbrosa, B. Carambolae, B. Papayea, B. dorsalis, B. caudata and B. albistrigata. Fruit fly species most widely found was B. carambolae the total number of 80 individiuals, whereas B. umbrosa total number of 24 individual, B. Papayea total number 48 individual, B. dorsalis total number of 7 individual, B. caudata total number of 74 individual, B. albistrigata total number of 3 individual.
\end{abstract}

Keywords: Fruit Flies, Orange, Villaga Danau Sati.

\section{PENDAHULUAN}

Kecamatan Rambah Samo memiliki 14 desa yang salah satunya bernama desa Danau Sati yang terletak antara desa Pesagang dan Kubu-Baru/Hasahatan. Di Kecamatan Rambah Samo terdapat perkebunan jeruk limau (Citrus limon) yang merupakan salah satu sentral produksi jeruk. Perkebunan ini telah berjalan selama 4 tahun yang dikelola petani. Jeruk limau memiliki rasa yang begitu sedap, segar dan mengandung banyak vitamin $\mathrm{C}$ begitu juga mengandung mineral-mineral untuk kesehatan tubuh bila dikonsumsi.

Pertanian jeruk di Kecamatan Rambah Samo menjadi sumber pendapatan bagi petani jeruk, namun dalam merawat kebun jeruk tersebut, petani mengeluh karena banyaknya buah yang busuk serta buah jeruk yang rontok, diduga akibat penyakit dan juga hama. Kerusakan lalat buah diberikan contoh seperti di Australia, dengan kerusakan lebih kurang 100 juta dolar AS setara 500 triliun rupiah per
12 bulan jika lalat buah ini tidak dikendalikan dapat menyebabkan kerugian (Siwi \& Hidayat, 2004).

Hama yang sangat ganas pada tanaman hortikultura salah satunya adalah hama lalat buah lebih dari 100 jenis, tanaman hortikultura menjadi target serangannya. Kerusakan akibat serangan hama lalat buah dapat berakibat kepada kehilangan hasil panen mencapai $80 \%$. (Syahfari \& Mujiyanto, 2013).

Pada dasarnya lalat buah menyukai bau makanan, warna, rasa buah dan daging buah yang bervariasi (Nif'atin, 2015). Lalat buah ini dapat merugikan tanaman petani secara kualitatif maupun kuantitatif. Kerugian kualitatif yaitu buah yang cacat berupa bercak, busuk, berlubang dan terdapat larva lalat buah yang akhirnya kurang diminati konsumen sedangkan kerugian kuantitatif kurangnya produksi buah akibat rontoknya buah yang terserang sewaktu buah masih muda ataupun buah yang rusak serta busuk yang tidak laku dijual (Rahayu, 2011). Berbagai usaha 
Fitriani, V., Karno, R., Brahmana, EM. 2018. Identifikasi Lalat Buah (diptera: Tephritidae) pada Kebun Jeruk di Kecamatan Rambah Samo Kabupaten Rokan Hulu. Sainstek : Jurnal Sains dan Teknologi. 10 (2) : 29-32

pengendalian lalat buah telah dilakukan secara tradisional atau menggunakan insektisida kimia. Untuk mencegah serangan hama lalat buah secara tradisional dilakukan dengan cara membungkus buah dengan berbagai alat pembungkus, antara lain kantong plastik, kertas koran dan daun kelapa (Muryati, Hasyim, \& Kogel, 2007).

Menurut Manurung, Prastowo, \& Tarigan (2012) sebagai salah satu serangga pada tanaman hortikultara daerah tropis dan subtropics, lalat meletakkan telurnya di bawah kulit buah, setelah telur menetas menjadi larva, larva akan memakan daging buah sehingga buah lebih cepat busuk dan mudah jatuh dari pohon. Sampai saat ini belum ada yang memberikan informasi mengenai spesies lalat buah di kebun jeruk Kecamatan Rahmah Samo Kabupaten Rokan Hulu, maka dipandang perlu untuk dilakukan penelitian.

\section{METODE PENELITIAN}

Pelaksanan Penelitian dimulai pada bulan Maret sampai dengan Mei 2018 di perkebunan jeruk di Desa Danau Sati Kecamatan Rambah Samo Kabupaten Rokan Hulu dan dibawa ke Laboratorium Biologi Universitas Pasir Pengaraian untuk diidentifikasi.

Alat yang digunakan yaitu mikroskop, kotak spesimen, cawan petri dengan diameter $15 \mathrm{~cm}$, tabung pial, kuas, meteran, gunting, pinset, botol bekas air mineral $600 \mathrm{ml}$ dan kamera handphone. Sedangkan bahan yang digunakan yaitu: tanaman jeruk, jarum suntik, kain kasa, kapas, kertas label, tali rafia, petrogenol (senyawa pemikat), air dan alkohol $70 \%$. Penelitian deskriptif kuantitatif dengan metode survei, Purposive sampling menjadi teknik pemilihan sampel pada penelitian ini.

Cara kerja di lapangan dengan memanfaatkan botol air mineral $600 \mathrm{ml}$ yang sudah dipakai kemudian dilubangi sebelah kanan juga sebelah kiri kemudian menjadi seperti pintu dalam mempermudah lalat buah masuk. Tali raffia menjadi pengikat kapas, kemudian kapas menjadi melintang atau memanjang dan dilakukan pijatan supaya kapas menjadi gulungan padat. Tali rafia yang ada di dalam botol dikeluarkan melalui kepala botol. Setelah itu, mengikat separoh tali rafia kepada bagian atas botol atau menutup kepala botol agar tali rapi. Kapas menggantung pada bagian tengah botol. Kemudian teteskan petrogenol (senyawa pengikat untuk mengendalikan lalat buah) mengunakan jarum suntik pada kapas dengan jumlah $0,25 \mathrm{cc} / \mathrm{ml}$. isi air ke dalam perangkap sebanyak $150 \mathrm{ml}$ tujuannya agar perangkap tidak mudah goyah oleh angin. Perangkap siap dipasang pada termpat yang telah disediakan. Pengambilan sampel akan dilakukan pada pagi (10.00-14.00) dan sore (16.00-18.00) lalat buah akan masuk ke dalam perangkap. lalat buah yang didapatkan dipindahkan kedalam tabung pial yang diberi alkohol 70\% secukupnya menggunakan pinset. Sampel diberi label (Maysaroh, Yolanda, \& Lubis, 2015). Cara kerja di laborarium yaitu, Sampel yang sudah dipadatkan masukkan ke dalam tabung pial kemudian di keluarkan dan diletakkan di atas cawan petri. Kemudian diamati menggunakan mikroskop dengan memperhatikan morfologi dari lalat buah yaitu bagian kepala (caput), dada (toraks), dan perut (abdomen).

\section{HASIL DAN PEMBAHASAN}

\section{Pelestarian Tanaman Jeruk}

Lokasi tanaman kebun jeruk berbatasan dengan ladang padi dan kebun jeruk pada bagian barat, berbatasan dengan kelapa sawit dan kebun jeruk pada bagian timur, berbatasan dengan tanaman ladang sayuran pada bagian selatan. Tanaman yang ada di areal perkebunan jeruk sebagai tempat penelitian memiliki luas tanah 2 hektar jumlah tanaman 600 batang. Pemeliharaan kebun jeruk petani melakukan dengan pemupukan secara rutin dan membersihkan kebun jeruk dengan cara pembersihan rumput liar dengan menggunakan mesin pemangkas rumput secara 2 bulan sekali, pembersihan piringan tanaman sekaligus menggemburkan tanah di pinggiran. Petani jeruk juga melakukan pemangkasan ranting dan pengendalian hama menggunakan insektisida. 
Fitriani, V., Karno, R., Brahmana, EM. 2018. Identifikasi Lalat Buah (diptera: Tephritidae) pada Kebun Jeruk di Kecamatan Rambah Samo Kabupaten Rokan Hulu. Sainstek : Jurnal Sains dan Teknologi. 10 (2) : 29-32

Tabel 1. Jenis Lalat Buah yang Terperangkap pada Kebun Jeruk di Kecamatan Rambah Samo Kabupaten Rokan Hulu.

\begin{tabular}{|c|c|c|c|c|}
\hline No & Jenis (Spesies) & $\begin{array}{c}\text { Jenis } \\
\text { Kelamin } \\
(\lesssim)\end{array}$ & $\begin{array}{c}\text { Jenis } \\
\text { Kelamin } \\
(q) \\
\end{array}$ & Jumlah individu \\
\hline 1 & Bactrocera umbrosa & - & $\sqrt{ }$ & 24 \\
\hline 2 & Bactrocera carambolae & $\sqrt{ }$ & - & 80 \\
\hline 3 & Bactrocera papayea & $\sqrt{ }$ & - & 48 \\
\hline 4 & Bactrocera dorsalis & $\sqrt{ }$ & - & 7 \\
\hline 5 & Bactrocera caudata & - & $\sqrt{ }$ & 74 \\
\hline 6 & Bactrocera albistrigata & - & $\sqrt{ }$ & 3 \\
\hline \multicolumn{3}{|c|}{ Jumlah Individu } & \multicolumn{2}{|r|}{236} \\
\hline
\end{tabular}

$$
\text { Keterangan: } \begin{aligned}
\sqrt{ } & =\text { Ada } \\
- & =\text { Tidak Ada } \\
\delta & =\text { Kelamin Jantan } \\
& =\text { kelamin betina }
\end{aligned}
$$

\section{Jenis Lalat Buah Teridentifikasi}

Penelitian membuktikan lalat buah yang terperangkap menggunakan petrogenol berjumlah 236 individu dari kebun jeruk di Kecamatan Rambah Samo Kabupaten Rokan Hulu. Berdasarkan hasil identifikasi mengacu pada buku pedoman identifikasi hama lalat buah (Siwi \& Hidayat, 2004) dengan membandingkan morfologi meliputi bentuk toraks, sayap dan abdomen. Jenis lalat buah yang ditemukan pada penelitian terdapat enam spesies yaitu Bactrocera umbrosa, Bactrocera carambolae, Bactrocera papayea, Bactrocera dorsalis, Bactrocera caudata dan Bactrocera albistrigata. (Sastono, Wijaya, \& Adnyana, 2017) menyatakan zat pemikat Metyl Eugenol menjangkau area yang lebih luas.

Dari Tabel 1 dapat dilihat spesies yang paling banyak ditemukan yaitu Bactrocera carambolae sebanyak 80 individu. Minggu 1 Perangkap menggunakan petrogenol pada hari pertama mendapatkan 20 individu, hari kedua meningkat menjadi 45 individu, setelah minggu pertama selesai, minggu selanjutnya tidak dapat melakukan penelitian karena terjadi hujan. Seterusnya dilanjutkan minggu ke 3 , di hari ketiga dan keempat mendapatkan 65 individu, sehingga insektisida pada perangkap berkurang dan membuat aktifitas lalat buah menjadi meningkat. Minggu ke 4 hari kelima berjumlah 68 individu dan hari keenam menurun menjadi 38 individu disebabkan karena petani baru melakukan pengedalian hama 4 hari sebelum dilakukan penelitian hingga lalat buah sangat sedikit didapatkan. Lalat buah yang terperangkap dengan menggunakan perangkap petrogenol banyak yang berjenis kelamin $\hat{\partial}$ berjumlah 135 individu sedangkan berjenis kelamin $q$ berjumlah 101.

\section{KESIMPULAN}

Berdasarkan hasil penelitian yang telah dilakukan dapat disimpulkan bahwa Enam spesies lalat buah yang telah diidentifikasi dari 236 individu yang menyerang perkebunan jeruk di Kecamatan Rambah Samo Kabupaten Rokan Hulu tahun 2018 adalah Bactrocera umbrosa, B. Carambolae, B. Papayae, B. Dorsalis, B. Caudata, B. Albistrigata. Sebanyak 24 individu dari jenis Bactrocera umbrosa, 80 individu dari jenis Bactrocera carambolae, 48 individu dari jenis Bactrocera papayea, 7 individu dari Bactrocera dorsalis, 74 individu dari Bactrocera caudata, 3 individu dari Bactrocera albistrigata. 


\section{DAFTAR KEPUSTAKAAN}

Manurung, B., Prastowo, P., \& Tarigan., E. E. (2012). Pola aktivitas harian dan dinamika Populasi lalat buah (Bactrocera dorsalis complek) pada pertanaman jeruk di dataran tinggi Kabupaten Karo Provinsi Sumatera Utara. Jurnal HTP Tropika, 12(2), 103-110.

Maysaroh, S., Yolanda, R., \& Lubis, R. R. (2015). Identifikasi lalat buah (Diptera: Taphritidae) pada perkebunan cabai merah (Capsicum annum L) di Jalur 03 Desa Kepenuhan Sejati Kecamatan Kepenuhan Kabupaten Rohan Hulu. Jurnal Ilmiah Mahasiswa FKIP Prodi Biologi, 1(1).

Muryati, Hasyim, A., \& Kogel, W. J. d. (2007). Distribusi Spesies Lalat Buah di Sumatera Barat dan Riau. Jurnal Holtikultura, 17(1), 61-68.

Nif'atin, T. . (2015). Surveilensi lalat buah Bactrocera spp. (Diptera: Tephritidae) pada komoditas pepaya di Kabupaten Jember. Skripsi. Fakultas Pertanian Universitas Jember.
Rahayu, G. . (2011). Keefektifan tiga atraktan menggunakan bola pewarna dalam menangkap imago lalat buah pada jambu biji Kecamatan Tanah Sareal Kota Bogor. Skripsi. Fakultas Pertanian Institut Pertanian Bogor.

Sastono, I. W., Wijaya, I. N., \& Adnyana, I. M. M. (2017). Uji Efektivitas Perangkap Kuning Berperekat dan Atraktan terhadap Serangan Lalat Buah pada Pertanaman Jeruk di Desa Katung, Kecamatan Kintamani, Kabupaten Bangli. Jurnal Egroekoteknologi Tropika, 6(4).

Siwi, S. ., \& Hidayat, P. (2004). Taksonomi dan Bioekologi lalat Buah Penting di Indonesia (Diptera: Tephritidae) di Indonesia. Bogor. Balai besar penelitian dan pengembangan bioteknologi dan sumberdaya genetik pertanian.

Syahfari, H., \& Mujiyanto, D. (2013). Identifikasi hama lalat buah (Diptera: Tephritidae) pada berbagai macam buahbuahan. Jurnal Ziraa'ah, 36(1), 32-39. 